\title{
¿Se puede garantizar un contrato a través de un título valor?
}

\section{Can a security guarantee a contract?}

\section{Matthías Villavicencio Gomezjurado*}

Recibido / Received: 15/01/2021

Aceptado / Accepted: 24/10/2021

DOI: $10.18272 /$ ulr.v8i2.2163

\section{Citación:}

Villavicencio Gomezjurado, M. «¿Se puede garantizar un contrato a través de un título valor?». USFQ Law Review, Vol 8, no 2, octubre de 2021, pp. 1-13, doi: 10.18272/ulr.v8i2.2163.

\footnotetext{
Abogado asociado en el área de Litigios y Arbitraje en Robalino Abogados, Quito 170525, Pichincha, Ecuador. Correo electrónico: matthiasvillavicencio@gmail.com; ORCID iD: https://orcid.org/0000-0001-8807-5290
} 


\title{
RESUMEN
}

En la práctica comercial es común utilizar títulos valor -principalmente pagarés y letras de cambio- como garantías de una obligación contractual distinta. Un gran sector de la jurisprudencia nacional, empero, considera que al momento de girar un título valor como garantía, se pierde su mérito ejecutivo. Esta postura encuentra fundamento en el artículo 113 del Código de Comercio, que establece que los títulos valor contienen una promesa incondicional. A breves rasgos, por promesa incondicional se entiende que la exigibilidad del título no puede sujetarse a una condición. Justamente esta característica se ve comprometida si al momento de girar el título se condiciona su exigibilidad a que el deudor incumpla otro contrato. Los partidarios de esta postura son rígidos y no permiten esta práctica bajo ningún supuesto. Sin embargo, el uso de títulos valor como garantías es una modalidad tan arraigada en la costumbre comercial que vale la pena dedicar este ensayo al estudio de su factibilidad jurídica, indagar sus implicaciones y revisar los posibles escenarios en los cuales se pueda utilizar esta útil herramienta sin comprometer su carácter incondicional.

\section{Palabras clave}

Títulos valor; pagarés; letras de cambio; garantía; promesa incondiciona

\begin{abstract}
It is a common commercial practice to use securities - mainly promissory notes and bills of exchange - as guarantees of a different contractual obligation. A large section of Ecuadorian precedents considers that because of this practice, the security loses its validity. This position is based on Article 113 of the Ecuadorean Commercial Code, which states that securities incorporate an unconditional promise. In short, unconditional promise means that the enforceability of the security cannot be subject to a condition. This condition is compromised if at the time of issuing the security, its enforceability depends on the debtor breaching the original contract. Supporters of this position are vigorous and do not allow this practice under any circumstances. However, this modality is so ingrained in the commercial practice that it is worth dedicating this essay to the study of its legal feasibility, research its implications and inquire possible scenarios in which this helpful tool can be used without compromising the unconditional component of the security.
\end{abstract}

\section{KEYWORDS}

Securities; promissory notes; bills of exchange; warranty; unconditional promise 


\section{INTRODUCCIÓN AL PROBLEMA Y ESTADO ACTUAL DE LA CONTROVERSIA}

Los títulos valor son herramientas que permiten una tutela ágil y rápida de un derecho crediticio. Por este motivo, en el ámbito de una relación contractual es frecuente que el acreedor opte por garantizar un crédito a través de un título valor ${ }^{1}$ sobre otras figuras contractuales (como la prenda o el garante). Sin embargo, cuando se llega a la vía ejecutiva, la realidad puede ser adversa para el acreedor, puesto que muchos jueces restan mérito ejecutivo a un título si se descubre que se trata de una garantía.

Ciertamente, de un análisis a los juicios ejecutivos se observa que el giro en garantía es una excepción común alegada por los deudores demandados. No obstante, las resoluciones jurisprudenciales no son unánimes; así como han aceptado, han negado la ejecución de garantías contenidas en los títulos valor.

Por una parte, la jurisprudencia mayoritaria tiende a fallar en contra del uso de títulos valor como garantías. Por ejemplo, la Corte Suprema de Justicia, en Sentencia No. 282 de 1996, resolvió que "para que proceda la acción cambiaria, ha de incorporar una obligación clara, pura y líquida, y que al girar una letra por causa de garantía se está incorporando una obligación condicional, por lo que no podrá prosperar la acción cambiaria por la vía ejecutiva". ${ }^{2}$ En otra ocasión, la misma Corte consideró:
Si la letra en cuestión fue girada en garantía, tenemos que no se trata de una orden incondicional de pagar una cantidad determinada, no vale como letra de cambio, al tenor del artículo 411 [actualmente 113 del Código de Comercio]. Utilizar un formulario de letra de cambio para otorgar una garantía, es desnaturalizarlo, dejándolo sin valor (énfasis añadido). ${ }^{3}$

Se aprecia que es normal que las salas civiles se opongan a la ejecución de este tipo de títulos. ${ }^{4}$ En la causa 17230-2019-01576, la corte fundamentó su archivo de la demanda de la siguiente forma:

Examinado el documento que consta a fojas 1, se advierte que ha sido suscrito en la misma fecha en la que se firmó el Convenio de Incentivo y Entrega de Fondos [contrato principal], con el fin de garantizar el dinero entregado al hoy demandado, lo que impide calificar al documento como pagaré a la orden, esto es que no

\footnotetext{
Nota: Para efectos de esta investigación se utiliza el término "títulos valor" para referirse principalmente a pagarés y letras de cambio. Se excluye expresamente este término para referirse a títulos que incorporen una prestación distinta a "dar dinero".

2 Causa 1329-93, Corte Suprema de Justicia, Primera Sala de lo Civil y Mercantil, en sentencia No. 282 de 23 de abril de 1996, párr. 6.

3 Gaceta Judicial Año XCII, Serie XV, No. 15. Quito, 11 de diciembre de 1992, 4468.

4 Gaceta Judicial Ańo LIII, Serie VI, No. 10. Quito, 16 de julio de 1953: "si al girar el documento se hace constar una condición a cuyo cumplimiento se subordina su eficiencia, no valdrá como letra de cambio”.
} 
contiene una obligación incondicional pues se encuentra ligado al convenio antes anotado. ${ }^{5}$

Se concluye que las cortes ecuatorianas, de manera general, han considerado a esta práctica como una suerte de "causal" para que no prospere la acción cambiaria.

La doctrina también se suma a este criterio. Montoya Alberti considera que "una orden incondicional debe entenderse como una orden de pago sin condiciones, que no admite un acontecimiento -como sí lo hace la garantía- para que sea efectivo su cumplimiento. Esto basta para que la figura de la letra de cambio en garantía sea descartada". ${ }^{6}$

Por otra parte, sí existen precedentes -aunque muy escasos- que han aceptado la ejecución de títulos valor girados como garantías. La Corte Provincial de Pichincha aceptó un recurso de apelación planteado por el acreedor y fundamentó: "[e]n vista de que se le califique como título valor no significa que la operación en función de la misma sea para ello, sino es una especie genuina de operación cambiaria, de garantizar sí, pero el pago de una obligación de la misma naturaleza” (énfasis ańadido). ${ }^{7}$ En el caso de Perú, la Casación 23842008 estableció textualmente que "no existe impedimento legal a efecto que un título valor entregado en garantía - a decisión del acreedor- sea ejecutable vía proceso ejecutivo como en el presente caso". ${ }^{8}$ Por último y remitiéndose a la doctrina, Santiago Andrade demuestra su apoyo a esta postura y expone que en ciertas ocasiones " $[1]$ a causa de la letra de cambio consiste en destinar la letra a reforzar esa deuda extra cambiaria. El acuerdo por el cual deudor y acreedor deciden reforzar dicho crédito por la emisión de una letra de cambio es la llamada convención ejecutiva” (énfasis añadido). ${ }^{9}$

Ambas posturas tienen su lógica y deben ser estudiadas. Sin ánimo de adelantar conclusiones ni de optar por un punto de vista en concreto, el objetivo de este ensayo es el examen del fundamento legal de esta práctica y sus posibles transgresiones a la naturaleza cambiaria de los títulos valor.

\section{LA PROMESA INCONDICIONAL Y EL INCUMPLIMIENTO}

Como se puede concluir del capítulo anterior, las cortes justifican sus negativas frente a los títulos valor en garantía, sobre la base del principio de incon-

5 Causa No. 17230-2019-01576, Corte Provincial de Pichincha, Sala Especializada de lo Civil y Mercantil, 26 de enero de 2020, 16.

6 Hernando Montoya Alberti, Problemas en la emisión de títulos valores: enfoque jurisprudencial (Lima: Gaceta Jurídica, 2009), 37.

7 Causa No. 17230-2016-01848, Corte Provincial de Pichincha, Sala Especializada de lo Civil y Mercantil, 19 de noviembre de 2020, 3

8 Casación 2384-2008, Sala de Casación, Sala Civil Transitoria, 8 de julio de 2009, párr. 6.

9 Santiago Andrade Ubidia, Los Títulos Valor en el Derecho Ecuatoriano, Tercera Edición (Quito: ABYA YALA, 2006), 313. 
dicionalidad. ${ }^{10}$ En tal virtud, este capítulo estudia este concepto, así como sus implicaciones en los títulos valor y en las garantías.

El nuevo Código de Comercio establece en su artículo 113 que "la letra de cambio es un título valor de contenido crediticio, por el cual una persona denominada girador ordena a otra [...] el pago incondicional a un tercero". ${ }^{11}$ Este requisito también está presente en los endosos (artículo 139), los pagarés (artículo 187) y las facturas comerciales (artículo 203). Peña Nossa explica que "la promesa incondicional indica que el obligado se compromete fuera de toda condición". ${ }^{12}$ Concretamente en el ámbito de los títulos valor, López Arévalo aclara que "[l]a aceptación debe ser pura y simple, y no puede estar sujeta a modo o condición de ninguna naturaleza”. ${ }^{13}$

$\mathrm{Al}$ respecto, Lorenzetti define a la condición como "un acontecimiento futuro e incierto del cual depende el nacimiento o extinción de una obligación". ${ }^{14} 15$ Parraguez Ruiz aclara que la futureidad consiste en que "la exigibilidad de una obligación ha de estar concebida para que ocurra con posterioridad a la estipulación"16, mientras que la incertidumbre hace referencia a que "existe duda sobre la producción del hecho futuro [...] y las partes son ignorantes [sobre si el hecho realmente va a ocurrir] al momento de pactar la condición”. ${ }^{17}$

Antes de estudiar las implicaciones teóricas de un título valor que garantice una obligación, es pertinente repasar brevemente el concepto de garantía. Parraguez Ruiz expresa que las garantías "tienen como objetivo garantizar al acreedor la satisfacción de su crédito". ${ }^{18}$ Meza Barros -al referirse a la garantía en la compraventa- explica que "se encuentra encaminada a asegurar el pago del precio". ${ }^{19}$ Finalmente, Lorenzetti lo expone de la siguiente forma: "la garantía $[. .$.$] pretende brindar una seguridad respecto del cumplimiento de otro$ contrato" ${ }^{20}$ En tal virtud, el contrato de garantía no es más que aquel que tiene como objeto precautelar el derecho de crédito de la parte acreedora en el supuesto de que su contraparte incumpla el contrato.

La característica más importante de la garantía -para efectos de este ensayoes que se trata de un contrato accesorio. Aquello conlleva una consecuencia

10 Nota: obsérvese que las cuatro sentencias contrarias a los títulos valor en garantía utilizan la base de la promesa incondicional para motivar sus archivos.

11 Artículo 113, Código de Comercio, Registro Oficial Suplemento 497, 29 de mayo 2019.

12 Lisandro Peńa Nossa, De los Títulos Valores (Rosario: Ecoe Ediciones, 2016), 613.

13 William López Arévalo, El Proceso Ejecutivo, Los Titulos Ejecutivos y las Medidas Precautorias en el Ecuador (Quito: Ed. Jurídica del Ecuador, 2014), 103.

14 Ricardo Lorenzetti, Tratado de los Contratos (Buenos Aires: Rubinzal Culzoni editores, 2001), 311.

15 Cabe mencionar que las condiciones entran en la clasificación de obligaciones modales, que difieren de las puras y simples. Ver, René Abeliuk Manasevich, Las Obligaciones, Tomo I (Santiago de Chile: Editorial Jurídica de Chile, 1993), 276.

16 Luis Parraguez Ruiz, Manual de Derecho Civil Ecuatoriano, Teoria de las Obligaciones, Vol. 1 (Quito: UTPL, 2006), 145.

17 Ibid., 147.

18 Luis Sergio Parraguez Ruiz, Régimen Jurídico de los Bienes (Quito: Ed. Cevallos, 2015), 59.

19 Ramón Meza Barros, De las Fuentes de las Obligaciones, Tomo I (Santiago de Chile: Editorial Jurídica de Chile, 1995), 130.

20 Ricardo Lorenzetti, Tratado de los Contratos, 26. 
práctica: lo accesorio sigue la suerte de lo principal. ${ }^{21}$ Dicho de otro modo, la extinción del contrato principal por cumplimiento de las obligaciones, también extingue la garantía.

En conclusión, el problema con los títulos valor girados en garantía radica en que el concepto de "promesa incondicional" es incompatible con el concepto de "garantía". Se mencionó que este último concepto está directamente vinculado al incumplimiento. En el hipotético caso de que un título valor garantice otro contrato, se estaría condicionando su exigibilidad a que dicho contrato se incumpla, lo que le resta su carácter de incondicional. Este ha sido el principal argumento utilizado tanto por deudores como por jueces para desestimar una acción cambiaria de cuyo título se deduce una garantía. Este problema se desarrollará en el capítulo siguiente.

\section{LOS TÍTULOS VALOR Y SU CONTRATO ORIGINARIO}

Generalmente, un título valor se gira en torno a una relación comercial en la cual se pretende asegurar el cumplimiento de las prestaciones contractuales. En materia cambiaria, este contrato se conoce como "originario". Dicha aclaración tiene relevancia porque el título valor solo garantiza a su contrato original. Este capítulo estudia las relaciones y vínculos existentes entre un título y su contrato originario al momento de ser girado, así como define las circunstancias en las cuales se pueda considerar a la garantía como un legítimo impedimento en la ejecución de un título.

En primer lugar, es necesario definir al contrato originario como el negocio jurídico que dio vida al título valor, así como sus antecedentes y el marco jurídico en el que se le desarrolló su origen. Santiago Andrade profundiza respecto a lo que él denomina "relación fundamental" y expone: "de acuerdo con la doctrina, con relación a la causa lícita, se ha de anotar que la letra de cambio es girada o librada, por lo general, como consecuencia de un negocio jurídico extra cambiario, existente entre librador y primer tomador, que se llama relación fundamental". ${ }^{22}$

Todo título tiene una relación fundamental. Puesto que los títulos valor por excelencia contienen un derecho crediticio, siempre va a ser necesario un acontecimiento jurídico que sea la contraprestación de dicho crédito; caso contrario, no se podría justificar la existencia de dicho crédito en favor del beneficiario.

21 Arturo Alessandri, Manuel Somarriva y Antonio Vodanovic, Tratado de las Obligaciones, Vol. I. (Santiago de Chile: Editorial Jurídica de Chile, 1998), 95.

22 Santiago Andrade, Los Titulos Valor, 313. 
Cabe agregar que un título no solo tiene un contrato originario, sino que al momento de ser girado, dicho contrato debe tener una prestación pendiente. Caso contrario, esto es que el contrato se encuentre completamente cumplido, no existiría un móvil para que una de las partes gire un título en favor de la otra. Asimismo, al estar el contrato extinto, este no puede servir como relación fundamental, y sin esto no existe un título.

Ahora bien, ¿qué papel juega esta prestación pendiente en el título? Es lógico que el objeto básico del título sea reforzar dicha prestación aún debida en su contrato original para poder ejecutarla -valga la redundancia- en la vía ejecutiva. Desde la perspectiva de Santiago Andrade, "[l]a causa de la letra de cambio consiste en destinar la letra a reforzar esa deuda extra cambiaria. El acuerdo por el cual deudor y acreedor deciden reforzar dicho crédito por la emisión de una letra de cambio es la llamada convención ejecutiva" (énfasis ańadido). ${ }^{23}$ En otras palabras, el título es a priori una garantía a su relación fundamental.

Si respecto al tema de fondo se adopta una postura bastante restringida -como es el caso de nuestra jurisprudencia- se llega a una contradicción con los títulos valor en sí. Si la primera premisa es que los títulos valor en garantía no valen, y la segunda premisa es que todos los títulos son garantías, la conclusión es que ningún título valor vale. Este silogismo debe ser necesariamente equívoco, pues niega la existencia misma de los títulos valor.

Por tal motivo es evidente que no se pueden restringir los títulos valor en garantía, sin más. Aquello tampoco significa, empero, que se puede desnaturalizar un título valor al punto que los títulos valor garanticen absolutamente todo tipo de obligaciones y se olvide su carácter incondicional. En conclusión, no se debe restar mérito ejecutivo a un título por el solo hecho de verificar una garantía, sino que es necesario realizar un examen al caso concreto y verificar si existe transgresión a la incondicionalidad del título. Los supuestos serán estudiados de manera concreta en los subtítulos siguientes.

\subsection{LA GARANTÍA DE UNA OBLIGACIÓN DE LA MISMA NATURALEZA}

Los títulos valor comprenden un derecho crediticio de dar dinero. La Corte Suprema de Justicia manifestó que "[n]o conteniendo el mismo instrumento la obligación de pagar una suma de dinero, sino quintales de arroz, no es pagaré a la orden, pues es de su esencia el dinero, lo único que es redituable en intereses". ${ }^{24}$ Del mismo modo, Santiago Andrade expone que "el objeto idóneo u objeto lícito de una letra de cambio será únicamente la promesa

23 Ibid. 312.

24 Gaceta judicial Año LII, Serie VII, Nro. 6, Quito, 27 de enero de 1952, 567. 
incondicional de pagar una suma determinada de dinero". ${ }^{25}$ Por su parte, Alvear Icaza explica que el pagaré es título valor de crédito que implícitamente significa una promesa incondicional de pago de una suma de dinero. ${ }^{26} \mathrm{~A}$ todas luces, la naturaleza de la prestación contenida y debida en el título valor es "dar dinero". En relación con el tema de fondo, ¿qué sucede cuando la obligación garantizada en el título también consiste en "dar dinero"?

En este caso, las partes sí pueden suscribir un título valor que garantice este tipo de obligaciones. Incluso, nuestra jurisprudencia nacional ha permitido esta modalidad. Se resolvió que "[e]n vista de que se le califique como título de crédito no significa que la operación en función de la misma sea para ello, sino es una especie genuina de operación cambiaria, de garantizar sí, pero el pago de una obligación de la misma naturaleza" (énfasis añadido). ${ }^{27}$

Del criterio de la Corte se infiere que esta práctica es perfectamente plausible por cuanto la prestación debida es la misma. La obligación contenida en el contrato principal y la obligación del título valor son tan idénticas que de cierta forma se confunden entre sí, al punto que aparentan ser una misma obligación. Al cumplir el contrato principal se cumple -a su vez- con el título valor. Personalmente, creo que éste es un supuesto en el cual las partes en la relación subyacente se remiten al título valor. Esto quiere decir que no existen dos obligaciones (el contrato y el título), sino que el título es el modo de cumplir el contrato principal.

A aquello que he llamado "confusión" le sucede una incógnita muy interesante respecto al efecto de utilizar un título valor dentro de una relación contractual. Un posible efecto consiste en que el título valor opera de manera parecida a la novación del contrato originario. Esto implica que al entregar el título se considera al contrato como cumplido. Por tal motivo solo subsiste el título valor, incluso si el deudor no ha pagado. La otra forma de ver a esta modalidad es que el título es tan solo una herramienta que garantiza el pago, y por tal el contrato subsiste hasta que el deudor pague. Sin ánimo de alargar esta discusión, se cierra el debate aclarando que la diferencia práctica entre estas posturas radica que en la primera al acreedor solo le asiste la vía ejecutiva (como ejecución del título), mientras que en la segunda también se puede ejercer a través de la vía ordinaria (como incumplimiento del contrato).

No se contraviene con el principio de incondicionalidad por cuanto el título siempre se va a ejecutar. Si se cumple la obligación principal, se cumple con el título valor. Si se incumple la obligación principal, se ejecuta el título. La ejecución del título no se condiciona al incumplimiento de la obligación principal, pues en cualquiera de los supuestos (cumplimiento o incumplimiento del

25 Santiago Andrade, Los Títulos Valor, 318.

26 José Enrique Alvear Icaza, Manual Elemental de Derecho Mercantil Ecuatoriano (Guayaquil: Editorial Edino, 2006), 88.

27 Causa No. 17230-2016-01848, 3. 
contrato principal) se satisface el título valor. Tampoco existe incertidumbre respecto a su carácter ejecutivo.

Un supuesto sui generis es el de la cláusula penal. Es frecuente que en la práctica comercial se garantice a esta cláusula a través de un título valor. En este caso la distinción entre obligaciones de dar, hacer o no hacer, es en vano, pues el resultado siempre será el mismo: el título pierde su carácter ejecutivo. Esto se debe a que estamos frente a un claro supuesto de promesa no condicional, por cuanto no existe certeza en la exigibilidad de la cláusula penal. Por ende, aun si la penalidad es monetaria y el contrato contiene la obligación de dar, el título valor sobre una cláusula penal no vale.

A fin de realizar un análisis más específico, es procedente observar este examen con los contratos que comparten la naturaleza de "dar dinero". Entre los principales resaltan la compraventa, el arrendamiento y el préstamo de dinero. Si se gira un título valor para garantizar la prestación de dar dinero (el pago del precio, el pago del canon de arrendamiento o la devolución del dinero prestado), la obligación contenida en el título es exactamente la misma. Por ejemplo, en el caso de la compraventa, el pago del título valor también es el pago del precio. Cabe advertir, empero, que el título valor solo puede servir como garantía de la prestación de "dar dinero", por cuanto solo sobre estas obligaciones comparte similitud la naturaleza de los títulos valor. Retomando el ejemplo de la compraventa, el título valor no podría garantizar la obligación de entrega de la cosa.

Un supuesto interesante que puede ocurrir es que la contraprestación de la obligación garantizada no se cumpla, o se cumpla de manera imperfecta. Esta hipótesis se va a ilustrar con el siguiente ejemplo: A vende un celular a B, y B entrega un pagaré. ¿Qué sucede si A no entrega el celular? En un principio, si el vendedor (A) exige el pago del precio, al comprador (B) le asiste la exceptio non adimpleti contractus, ${ }^{28}$ ya que él tampoco ha cumplido con la entrega de la cosa. No obstante, si el vendedor (A) ejecuta el título valor, por principio de abstracción el comprador (B) no podría oponer dicha excepción, pues se basa en otro contrato. En este caso la solución se resume en que el pagaré sí debería ejecutarse, pero el comprador (B) podría proponer una demanda ordinaria por incumplimiento del contrato en la entrega del celular. Por cuanto este problema se puede evitar, se considera que los títulos valor en garantía solo deberían valer cuando el acreedor haya cumplido a cabalidad con su prestación, de tal modo que solo quede pendiente la obligación sujeta a garantía.

Ahora bien, no quedaría fuera de lógica alegar que ambas obligaciones tienen fuentes distintas; y por ende, el cumplimiento de la obligación principal no

28 "En los contratos bilaterales ninguno de los contratantes está en mora, dejando de cumplir lo pactado, mientras el otro no lo cumple por su parte, o no se allana a cumplirlo en la forma y tiempo debidos". En Artículo 1568, Código Civil. 
significa el cumplimiento del título. Sin embargo, el título valor y el contrato principal comparten la misma causa originaria y consisten en la misma prestación. Consecuentemente, el pago de la obligación principal debe considerarse como el pago del título. Aquello fue confirmado por la Corte Suprema, que estableció que "[d]e suponerse lo contrario, se llegaría a la conclusión de que a una letra, pagada total o parcialmente, no se le podría oponer la excepción de pago y el deudor tuviera que abonar dos veces, no obstante de demostrar prueba plena de la extinción de la deuda". ${ }^{29}$ Por ende, en caso de que el acreedor pretenda ejecutar el título aún después de cumplida la obligación de dar dinero, al deudor le asiste la excepción de pago.

Tampoco existe un problema si el acreedor endosa el título en favor de un tercero. Este endoso fungiría como una suerte de "cesión de derechos", en la cual el endosatario toma el lugar del primer tenedor. Como la prestación contractual es la misma, el título puede circular libremente en el mercado de valores y servir como un medio de pago frente a terceros.

A modo de conclusión, este análisis es completamente coherente con la práctica comercial. Como se puede observar, la emisión de pagarés y letras de cambio casi siempre tienen como contrato originario un préstamo de dinero o la compra de mercadería. En ambos casos, la prestación aun pendiente es la de devolver o pagar dinero. Al existir homogeneidad con la naturaleza de los títulos valor, esta hipótesis es perfectamente posible y legalmente factible.

\subsection{LA IMPROCEDENCIA DE GARANTIZAR UNA OBLIGACIÓN DE NATURALEZA DISTINTA}

En el título anterior se resaltó que la naturaleza de la prestación de un título valor es "dar dinero". Por descarte, las obligaciones de distinta naturaleza son las obligaciones de "hacer", de "no hacer", y de dar algo distinto al dinero. En este sentido, los títulos valor en garantía no son compatibles con este tipo de obligaciones.

Cuando la obligación es de "dar dinero", el título siempre se cumple: ya sea por el cumplimiento de la obligación principal o por la ejecución del título. En el caso de obligaciones distintas, sucede exactamente lo contrario: o se cumple la obligación principal o se ejecuta el título valor. En el caso de obligaciones monetarias, la ejecución del título valor cumple con la obligación principal. Caso contrario (obligaciones distintas a dar dinero), el derecho monetario contenido en el título sustituye a la prestación incumplida en el otro contrato.

29 Gaceta Judicial, Ańo LVII, Serie. VIII, No. 14, Quito, 21 de marzo de 1957, 1380. 
Se plantea como ejemplo un contrato de obra, en el cual el artista se obliga a pintar el retrato de su contratista (obligación de hacer). El contratista paga por adelantado por el retrato, mientras que el artista gira un título valor como garantía en caso de que no cumpla con su obligación de pintar el retrato. En principio, el título valor solo podría ejecutarse si el artista incumple, por lo que pierde su carácter de incondicional.

En el caso contrario, es decir, si el artista cumple con el retrato, el tema se vuelve mucho más complejo y plantea un sinfín de problemas jurídicos. El inconveniente más agobiante versa sobre la falta de certeza sobre la suerte del título valor en un juicio. Una vez cumplida la obligación de pintar el cuadro, pueden ocurrir tres (iii) escenarios:

i. El juez no acepta la ejecución del título valor, pues siguiendo el principio de los contratos accesorios, al cumplirse la obligación principal se extingue el contrato de garantía, que en este caso es el título valor. Esto puede ser un problema si dicho título está circulando en manos de un tercero.

ii. El juez acepta la ejecución del título valor. Esta hipótesis se contrapone a la anterior, pero es plausible. El fundamento se basa en que la única manera de cumplir el título es a través de la prestación de "dar dinero". En este caso, la excepción de pago tampoco sería viable puesto que no existió un pago en dinero, sino únicamente la prestación de pintar un cuadro.

iii. El juez acepta la ejecución del título valor, esta vez sobre la base del principio de autonomía y abstracción. En virtud de estos principios, el artista no podría oponer ninguna excepción relativa al contrato de obra, ni alegar que se cumplió a cabalidad la obligación de pintar el cuadro.

Todos los escenarios son jurídicamente plausibles. Estas dos últimas hipótesis demuestran un caso de doble pago por una sola obligación. Además del problema de la incertidumbre, la ejecución depende del incumplimiento de la prestación de pintar el cuadro, ergo, no es una promesa incondicional. En todos los supuestos presentados existe una verdadera desnaturalización del título valor, pues éste pretende sustituir una prestación cuya naturaleza le es incompatible. Bien haría el juzgador en declarar a estos títulos como "no ejecutivos".

\subsection{UN PROBLEMA DE EQUIVALENCIA ENTRE LAS PRESTACIONES BEBIDAS}

Tras haber esgrimido a profundidad la naturaleza de las prestaciones garantizables, se concluye que girar un título valor como garantía presenta un problema aritmético: dos obligaciones como contraprestación de una sola. Ciertamente, 
en el contexto de esta operación contractual existen dos negocios jurídicos: un contrato y un título valor. El contrato contiene una obligación para cada una de las partes, mientras que el título solo obliga a una. Dicho de otro modo, existen dos fuentes contractuales que aparentemente contienen dos prestaciones que obligan al deudor (el contrato y el título) como contraprestación de una sola obligación por parte del acreedor (el contrato). Las matemáticas no cuadran; en razón de ello, se dice que existe una falta de "equivalencia". Un claro ejemplo de dos obligaciones por una sola contraprestación sucede cuando se garantizan obligaciones distintas a "dar dinero". Desde luego, si la obligación contractual es distinta a la prestación en el título, existen dos obligaciones distintas e incompatibles entre sí. Aquello implica que cualquier prestación por parte del deudor solo implica la solución a una obligación, lo que mantiene la otra pendiente. Retornando al ejemplo del artista, éste se ve obligado a dos prestaciones (pintar el cuadro y pagar el título) como recompensa de una sola prestación (pagar el cuadro).

Sin embargo, sucede todo lo contrario si la obligación garantizada es la de dar dinero. De ser así, las obligaciones que emanan del contrato y del título consisten, no solo en pagar, sino en pagar exactamente la misma cantidad. Consecuentemente, cualquier prestación realizada por el deudor debe atribuirse tanto al contrato como al título, y el deudor cumple una sola obligación por una sola prestación. Asimismo, como la forma de cumplir el contrato es mediante el pago del título, éste es siempre exigible e incondicional. Se concluye con toda certeza que existe armonía y sinalagma en el marco de la relación contractual.

\section{Conclusiones}

En el presente ensayo se ha presentado la práctica comercial de utilizar los títulos como garantías, así como las posturas que existen al respecto. Quedó claro que no se puede ser contendiente a esta herramienta de manera absoluta, puesto que hacerlo conlleva a la inevitable conclusión de que todo título es originalmente una garantía; y por ende ningún título vale. En este artículo se adopta una postura neutral en la que un título no pierde necesariamente su carácter ejecutivo por tratarse de una garantía.

En consecuencia, una segunda conclusión implica que la falta de mérito ejecutivo no depende per se de que el título advierta una garantía. Por tal motivo, los ministros de justicia cometen un error al desechar toda demanda ejecutiva cuyo título también sea una garantía. Lo correcto es realizar un análisis más exhaustivo y personalizado al caso, a fin de determinar la naturaleza de la prestación garantizada. En caso de tratarse de una obligación de "dar dinero", el título vale; caso contrario, pierde su mérito ejecutivo. 
El propósito de este trabajo ha sido el de ofrecer un nuevo enfoque respecto al uso adecuado de los títulos valor como garantías. Como última conclusión, se aprueba un uso limitado de los títulos como garantías, siempre que dicho uso no involucre incertidumbre respecto a la exigibilidad e incondicionalidad del mismo. 
